\title{
EXTRAÇÃO DE ÓLEO ESSENCIAL DA CASCA DA CANELA SASSAFRÁS
}

\author{
J. Seraglio ${ }^{1}$, D. S. Marcanzoni ${ }^{1}$, A. S. dos $\operatorname{Santos}^{1}$ e F. Dalcanton ${ }^{1}$ \\ Ambientais - Campus Chapecó - SC
}

E-mail para contato: janainaseraglio@unochapeco.edu.br ou fdalcanton@unochapeco.edu.br

\begin{abstract}
RESUMO: A canela sassafrás (Ocotea odorífera) é uma planta nativa da mata atlântica, extremamente explorada nas décadas de 60 à 90, principalmente na região de Vale do Itajaí (Santa Catarina), para a extração do óleo safrol, fazendo com que esta espécie entrasse na lista de plantas ameaçadas de extinção. Objetivou-se, então, buscar alternativas para melhorar o rendimento da extração do óleo essencial sem agredir o desenvolvimento da planta, utilizando sua casca. A metodologia empregada para a extração do óleo essencial foi a destilação com arraste de vapor d'água, usando a mesma massa de matéria prima (casca) e variando a quantidade de solvente (água) em relação ao tempo de extração, conforme planejamento fatorial completo $2^{2}$. Avaliando seu rendimento, constatou-se que o melhor resultado foi obtido com a maior quantidade de solvente $(250 \mathrm{~mL})$ e maior tempo de extração $(2,5 \mathrm{~h})$, sendo este de aproximadamente $2,35 \%$ de óleo essencial.
\end{abstract}

\section{INTRODUÇÃO}

A canela sassafrás conhecida cientificamente como Ocotea odorífera, é uma planta nativa da Mata Atlântica (MAAR e ROSENBROCK, 2012), que está presente nas florestas do sul da Bahia ao Rio Grande do Sul (CARVALHO, 1994). No século XX tornou-se ameaçada de extinção pela grande exploração da madeira para a extração do óleo essencial safrol (BRASIL, 1992; LORENZI, 2002).

Os óleos essenciais são misturas complexas lipofílicas com compostos aromáticos voláteis possuindo características odoríficas e líquidas, que podem ser extraídos de raízes, caules, folhas, flores, ou seja, de todas as partes da planta (SIMÕES e SPITZER, 2004). O teor de óleo essencial varia de acordo com as diferentes partes da planta e com as diferentes épocas e regiões de coleta (LORENZI e MATOS, 2002; MAGALHÃES, et al. 1997). Essas extrações podem ocorrer por destilação de arraste a vapor, compressão de vegetais ou uso de solventes (TRANCOSO, 2013). A destilação por arraste a vapor é um processo simples que consiste em submeter o material à ação do vapor d'água, que extrai o óleo contido nas glândulas vegetais. Os vapores são condensados e recuperados em um recipiente. O solvente e o óleo ficam em uma solução heterogênea devido à diferença de polaridade, com isso um reagente apolar é necessário ser adicionado para reagir com a substância orgânica (óleo essencial) e formar duas fases, orgânica e aquosa. Essas duas fases são separadas, onde apenas há interesse na fase orgânica, pois o óleo essencial está presente e precisa através da diferença de ponto de ebulição ser separado. Geralmente os reagentes são voláteis, implicando em uma separação mais rápida e precisa (SOUZA e CARVALHO, 2011).

O safrol que se apresenta em maior quantidade no óleo essencial extraído da canela sassafrás, é um composto orgânico de fórmula molecular $\mathrm{C}_{10} \mathrm{H}_{10} \mathrm{O}_{2}$, conhecido quimicamente por éter fenólico, com características de líquido incolor ou levemente oleoso, de densidade 
$1,096 \mathrm{~g} / \mathrm{ml}\left(\mathrm{a} 20^{\circ} \mathrm{C}\right)$ e ponto de fusão em torno de $11^{\circ} \mathrm{C}$ (MAAR e ROSENBROCK, 2012). É um componente aromático empregado nas indústrias químicas como matéria-prima para a síntese de dois derivados: a heliotropina, usada como componente de fragrâncias em indústrias de cosméticos e perfumarias, e o butóxido de piperonila, utilizado como agente sinergístico de inseticidas naturais (piretrium). Devido à ampla aplicação na indústria química, este produto possui grande demanda no mercado mundial, ultrapassando 3000 t/ano (PIMENTEL et al., 1998).

O Brasil tem lugar de destaque na produção de óleos essenciais, ao lado da Índia, China e Indonésia, que são considerados os quatro grandes produtores mundiais. Estes óleos essenciais, possuem grande aplicação na perfumaria, cosmética, alimentos e como coadjuvantes em medicamentos (REZENDE et al., 2009).

Com a expansão do mercado consumidor do óleo (safrol), a produção de óleos essenciais no Brasil é rentável. Diante da proibição do corte das árvores de canela sassafrás, é necessário incentivos governamentais e formação de parcerias com Centros de Pesquisa e Universidades para buscar alternativas para a extração deste óleo. Assegurando com isso, a reversão do quadro atual, mediante reflorestamentos e alternativas de manejo sustentável, que permitam a extração do óleo essencial sem o corte da árvore (KEIL, 2007). A extração do óleo essencial implica na disponibilidade de matéria prima, porém a canela sassafrás é uma árvore extinta no Brasil.

Devido a essas limitações, o principal objetivo do presente trabalho foi extrair o óleo essencial avaliando a quantidade de matéria prima usada, volume de solvente e tempo necessário para extração.

\section{MATERIAL E MÉTODOS}

Os ensaios das extrações de óleo essencial da canela sassafrás (Ocotea odorifera) foram realizados no Laboratório de Química Geral da Universidade Comunitária da Região de Chapecó (UNOCHAPECÓ).

Os galhos da canela sassafrás que foram usados para a retirada da casca decorreram de uma poda de árvores adultas encontradas no município de Chapecó, SC.

Para avaliar o rendimento de extração do óleo essencial variou-se o tempo de extração e o volume de solvente, ou seja, água, conforme o planejamento fatorial completo $2^{2}$ que pode ser visualizado na Tabela 1 . Sendo que esta apresenta a matriz do planejamento com os valores reais e os codificados, para a elaboração do modelo preditivo.

Tabela 1 - Matriz do planejamento fatorial completo $2^{2}$ para extração do óleo essencial com valores reais e codificados

\begin{tabular}{|c|c|c|}
\hline Ensaios & Tempo (h) & Volume de água $(\mathrm{mL})$ \\
\hline 1 & $1,5(-1)$ & $150(-1)$ \\
\hline 2 & $2,5(+1)$ & $150(-1)$ \\
\hline 3 & $1,5(-1)$ & $250(+1)$ \\
\hline 4 & $2,5(+1)$ & $250(+1)$ \\
\hline
\end{tabular}


Com base nesta matriz, os experimentos foram realizados em duplicata e de forma aleatória, sendo que nos ensaios variou-se tempo de extração em 1,5 e 2,5 h e quantidade de solvente (água) em 150 e $250 \mathrm{~mL}$. Para cada ensaio utilizou-se $10 \mathrm{~g}$ de casca de canela triturada em um liquidificador industrial. O óleo essencial foi obtido pela técnica de destilação por arraste a vapor (BECKER, et al., 1997).

Os experimentos procederam da seguinte forma: Colocou-se $10 \mathrm{~g}$ de canela sassafrás moída num balão de três bocas e adicionou-se o volume de solvente desejado (água). Iniciouse o aquecimento em mantas elétricas de aquecimento (Quimis), mantendo uma temperatura de modo a ter uma velocidade de destilação lenta, mas constante, após atingir o ponto de ebulição iniciou-se a contagem do tempo apresentado na Tabela 1. Continuou-se adicionando água através do funil de separação durante a destilação, para manter o nível original da água no balão.

O óleo e água coletados em um erlenmeyer no fim do condensador, foram transferidos para um funil de separação, sendo que o destilado com volume inicial de $150 \mathrm{~mL}$ foi extraído com duas porções de $10 \mathrm{~mL}$ de cloreto de metileno (Vetec); e outro com volume inicial de $250 \mathrm{~mL}$ foi extraído com duas porções $16,5 \mathrm{~mL}$ de cloreto de metileno. Separou-se em duas camadas e desprezou-se a fase aquosa. Secou-se a fase orgânica com sulfato de sódio anidro (Vetec). Filtrou-se a mistura em um funil de Hirsch, que fluiu diretamente para um balão de fundo chato, lavou-se com uma pequena quantidade de cloreto de metileno, deixando-o evaporar na capela do laboratório. Pesou-se os balões com óleo e calculou-se os rendimentos.

Os dados obtidos do planejamento fatorial foram tratados no software Statistica 7 e submetidos à análise de variância (ANOVA) ao nível de 5\% significância, podendo assim, montar um modelo preditivo dos ensaios realizados.

\section{RESULTADOS E DISCUSSÃO}

De acordo com os ensaios realizados, verificou-se que o maior rendimento da extração de óleo essencial foi obtido nos níveis positivos de cada fator analisado, obtendo-se um rendimento médio de 2,35\%, conforme demonstrado na Tabela 2.

Tabela 2 - Resultados obtidos a partir de duplicata da matriz de planejamento para extração do óleo essencial de canela sassafrás com valores reais e codificados

\begin{tabular}{|c|c|c|c|c|c|c|c|}
\hline Ensaios & $\mathrm{X}_{1}$ & $\mathrm{X}_{2}$ & Tempo $(\mathrm{h})$ & Solvente $(\mathrm{mL})$ & \multicolumn{2}{|c|}{ Rendimento (\%) } & Média (\%) \\
\hline 1 & -1 & -1 & 1,5 & 150 & 1,65 & 1,80 & 1,72 \\
\hline 2 & +1 & -1 & 2,5 & 150 & 1,70 & 1,76 & 1,73 \\
\hline 3 & -1 & +1 & 1,5 & 250 & 1,13 & 1,32 & 1,23 \\
\hline 4 & +1 & +1 & 2,5 & 250 & 2,25 & 2,45 & 2,35 \\
\hline
\end{tabular}

Segundo pesquisa realizada por Obrzut e Carvalho (2011) que utilizaram o aparelho Clevenger para extrair o óleo essencial dos ramos da canela sassafrás, obtiveram um rendimento de $1 \%$ de óleo em massa seca. Já Cansian et al. (2010) que utilizou o mesmo aparelho para a extração, mas realizou o experimento com a folha, obteve um rendimento de $1,2 \%$ de óleo essencial, com os materiais desidratados e moídos. Analisando esses dois resultados encontrados na literatura, se comparados com os obtidos no presente trabalho, pode-se afirmar que a extração por arraste a vapor é mais eficiente, obtendo um rendimento 
superior, mesmo sendo realizado em base úmida. A opção por trabalhar em base úmida foi determinada pela viabilidade, avaliando a quantidade de óleo extraído em base seca e base úmida, que não apresentaram diferenças significativas nos resultados.

Através dos dados da Tabela 2, pôde-se determinar quais parâmetros são significativos para a extração do óleo, conforme demonstra a Tabela 3.

Tabela 3 - Coeficientes de regressão, erro padrão, t-Student e p-valor para o planejamento fatorial $2^{2}$.

\begin{tabular}{|c|c|c|c|c|}
\hline Fatores & $\begin{array}{c}\text { Coeficientes de } \\
\text { regressão }\end{array}$ & Erro padrão & t-Student & p-valor \\
\hline Média & 1,756000 & 0,039241 & 44,74929 & 0,000001 \\
\hline $1 \mathrm{t}$ & 0,565500 & 0,078482 & 7,20550 & 0,001966 \\
\hline $2 \mathrm{~S}$ & 0,059500 & 0,078482 & 0,75814 & 0,490581 \\
\hline 1 by 2 & 0,557000 & 0,078482 & 7,09720 & 0,002082 \\
\hline
\end{tabular}

Sabe-se que os dados significativos devem possuir $\mathrm{p}<0,05$, portanto observou-se que o tempo de extração (t), bem como a interação do tempo com o volume de solvente (tS) foram significativos, porém o volume de solvente (S) como fator isolado, não é significativo neste estudo, não contribuindo para o aumento do rendimento. A partir da análise dos resultados, obteve-se o modelo codificado conforme a Equação 1, onde (t) equivale ao tempo de extração em horas e (tS) a interação do tempo com volume de solvente em $\mathrm{mL}$.

Rendimento $(\%)=1,76+0,57 \mathrm{t}+0,56 \mathrm{tS}$

A Tabela 4 apresenta a análise de variância (ANOVA) através da qual analisou-se a qualidade de ajuste do modelo codificado representado pela Equação 1.

Tabela 4 - Análise de variância (ANOVA) para o modelo codificado

\begin{tabular}{|c|c|c|c|c|}
\hline Fonte de variação & SQ & GL & MQ & Fcalculado \\
\hline Regressão & 1,260079 & 2 & 0,6300395 & 55,899166 \\
\hline Resíduo & 0,056355 & 5 & 0,011271 & \\
\hline Total & 1,316434 & 7 & & \\
\hline
\end{tabular}

$\mathrm{F}_{2,5,95 \%}=5,79 ; \mathrm{R}^{2}=95,72$.

Para que o modelo não seja apenas estatisticamente significativo, mas útil para fins preditivos, o valor de $\mathrm{F}$ calculado deve ser no mínimo quatro à cinco vezes maior que o $\mathrm{F}$ tabelado. Conforme a Tabela 4, o valor de F calculado é igual a 55,9, sendo este um valor aproximadamente dez vezes maior do que o F tabelado $(5,79)$, demonstrando desta maneira que o modelo apresentado pela Equação 1 é preditivo. Ainda de acordo com esta tabela, o coeficiente de explicação $\left(R^{2}\right)$ foi igual a 0,9572 , ou seja, o modelo explica $95,72 \%$ da variação das respostas preditas pelo mesmo.

Conforme o modelo encontrado verificou-se que passando do nível inferior para o nível superior de tempo de extração, ou seja, passando de 1,5 h para 2,5 h obtêm-se um 
aumento no rendimento da extração do óleo essencial próximo a 0,57\%. Avaliando a interação entre os fatores (tempo de extração e volume de solvente) observou-se um aumento no rendimento em torno de $0,56 \%$, quando em níveis positivos.

As Figuras 1 e 2 representam o ponto em que o rendimento do óleo teve seu maior valor atingido da interação entre tempo e volume de solvente, ou seja, quando trabalhou-se com os parâmetros nos seus níveis máximos. Percebeu-se ainda que o rendimento atingiu seu mínimo quando utilizado o maior volume de solvente e menor tempo de extração.
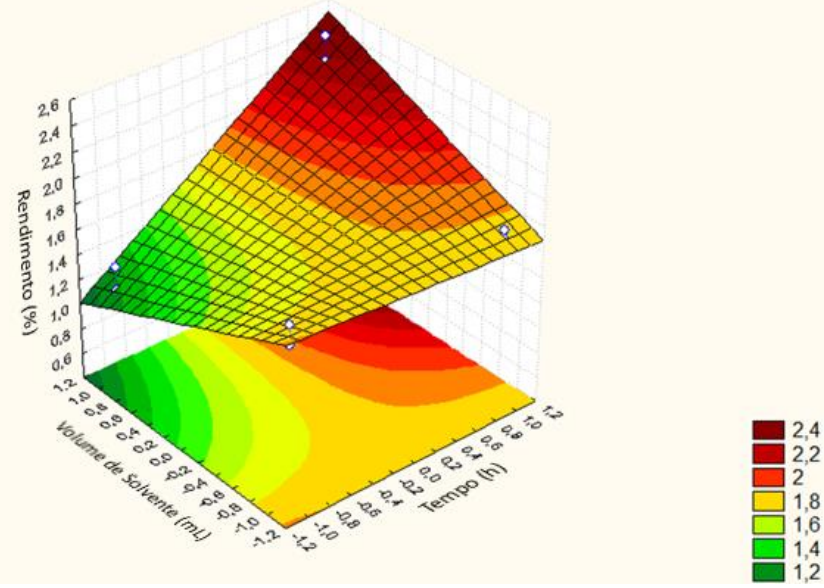

Figura 1: Superfície de resposta para o rendimento de óleo essencial relacionando com o tempo de extração e volume de solvente (3D).

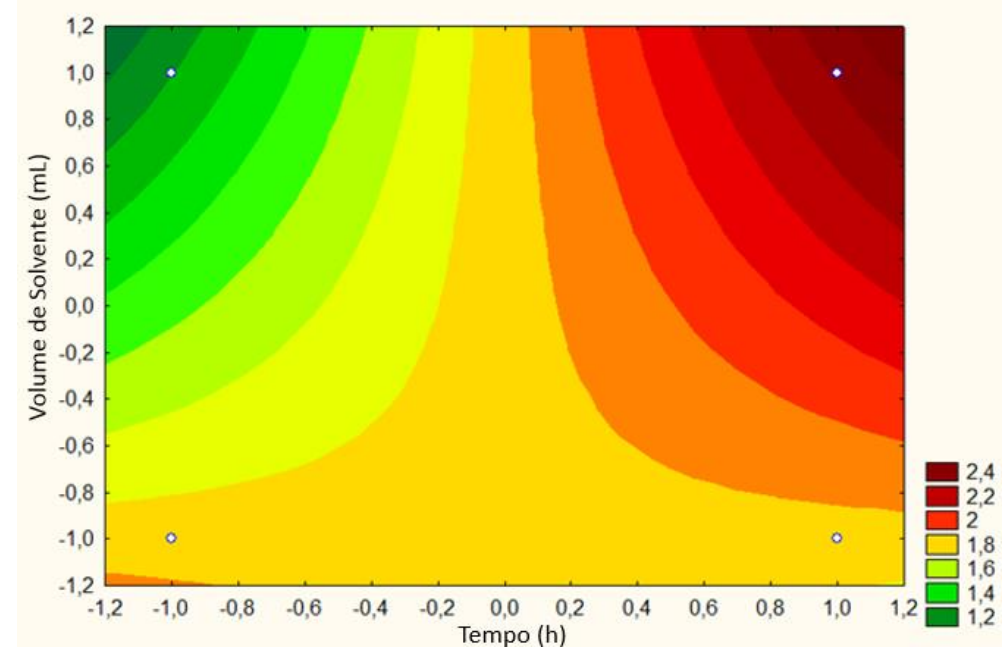

Figura 2: Curva de contorno para o rendimento de óleo essencial relacionando tempo de extração e volume de solvente (2D).

\section{CONCLUSÃO}

O objetivo da extração do óleo essencial de canela sassafrás usando partes regenerativas da planta foi alcançado, dado que todos os resultados encontrados foram superiores aos apresentados na literatura. O maior rendimento obtido neste trabalho foi $2,35 \%$ de óleo de essencial, com maior quantidade de solvente e o maior tempo de extração. 
O safrol que é um derivado do óleo essencial extraído da canela sassafrás, possui grande aplicabilidade em diversos ramos industriais, bem como alto valor comercial. Devido a esses fatores torna-se uma possível fonte de renda para pequenos e médio produtores. Além de incentivar reflorestamentos e a preservação desta planta que está na lista de plantas ameaçadas de extinção.

\section{AGRADECIMENTOS}

Os autores agradecem a Professora Natalia Paroul pela indicação do tema estudado, e ao Alencar Belotti e a Cristtiane Segatto, responsáveis pelo Viveiro Florestal da UNOCHAPECÓ, que realizaram a poda das árvores de canela sassafrás e forneceram a matéria prima utilizada para a realização do estudo.

\section{REFERÊNCIAS}

BRASIL. Portaria n. 006/92-N, de 15 de janeiro de 1992. Lista oficial de espécies da flora brasileira ameaçadas de extinção. Diário Oficial da República Federativa do Brasil, Brasília, v.130, n.16, p.870-872, 23 jan., 1992. Seção 1

BECKER, H. G. O. et al. Organikum: Química Orgânica Experimental. $2^{\text {a }}$ Edição. Lisboa: Fundação Calouste Gulbenkian, 1997. 1053 p.

CANSIAN, R. L. et al. Atividade antioxidante e antimicrobiana de extratos de canelasassafrás (ocotea odorifera (vell.) Rowher). Rio Grande do Sul: Perspectiva, v. 34, n.127, p. 123-133, 2010.

CARVALHO, P.E.R. Espécies florestais brasileiras: recomendações silviculturais, potencialidades e uso da madeira. Colombo, Empresa Brasileira de Pesquisa Agropecuária, Centro Nacional de Pesquisas Florestais, 1994.

LORENZI, H. Árvores Brasileiras: Manual de Identificação e Cultivo de Plantas Arbóreas Nativas do Brasil - Vol. 01, 2002, Canela Sassafrás - Ocotea odorífera, p.143.

LORENZI, H.; MATOS, F.J.A. Plantas medicinais no Brasil: nativas e exóticas. Instit. Plantarum, 2002.

KEIL, S. S. Crescimento, nutrição e composição do óleo essencial de Sassafrás submetido à fertilização e à omissão de nutrientes. p. 100. Tese de Doutorado - Silvicultura do Setor de Ciências Agrárias da Universidade Federal do Paraná. Curitiba, 2007.

MAAR, J. H.; ROSENBROCK, L. C. C. A química fina que poderia ter sido: a extração de óleo de sassafrás e de safrol no alto e médio vale do Itajaí. São Paulo: Scientiae St., v. 10, n. 4, p. 799-820, 2012.

MAGALHÃES, M. T. et al. Gengibre (Zingiber officinale roscoe) brasileiro: aspectos gerais, óleo essencial e oleoresina. Parte 2 - Secagem, óleo essencial e oleoresina. Rio de Janeiro: Ciênc. Tecnol. Aliment., v. 17(2), p. 132-136, 1997.

OBRZUT, V. V.; CARVALHO, R. I. N. Utilização do óleo essencial de sassafrás para o manejo da mariposa oriental em pessegueiro. Paraná: Rev. Acad., Ciênc. Agrár. Ambient., v. 9, n. 1, p. 65-71, 2011.

PIMENTEL, F.A. et al. Zoneamento e caracterização de habitats naturais de pimenta longa (Piper hispidinervum) no Acre. Acre: Boletim de pesquisa nº 20/Embrapa, 1998.

REZENDE, C. M. et al. Óleos essenciais no Brasil: aspectos gerais, desenvolvimento e perspectivas. Rio de Janeiro: Quim. Nova, v. 32, n. 3, p. 588-594, 2009.

SIMÕES, C. M. O.; SPITZER, V. Capítulo 18: Óleos voláteis. In: SIMÕES, C. M. O. et al. Farmacognosia: da planta ao medicamento. 5. ed. Porto Alegre: Ed. da UFRGS; Florianópolis:

Ed. da UFSC, 2004. p. 467-495. 
SOUZA, K. C. R.; CARVALHO, A. P. O. Extração do óleo essencial de Eucalyptus Globulus utilizando material alternativo no ensino de química. Cadernos e publicações de cursos: Química-Rev. Anhanguera, 2011. 